a otras obras que contribuyeron a desarticular el paradigma centrado en los "sectores populares". Estas contribuciones, bien diferentes entre sí, tienen algo en común: la solidez empírica que obra como base de sus hipótesis, una diferencia sustancial en relación con el paradigma que planteó la desaparición de la identidad clasista en ese período.

Federico Martocci (IESH - UNLPam)

$$
* * *
$$

\title{
Federico Lorenz, Algo parecido a la felicidad. Una historia de la lucha de la clase trabajadora durante la década del setenta (1973-1978), Buenos Aires, Edhasa, 2013, 344 pp.
}

Federico Lorenz presenta una investigación sobre el mundo del trabajo en los astilleros del partido de Tigre, provincia de Buenos Aires -principalmente Astarsa y, en menor medida, Mestrina- acerca del devenir de la agrupación sindical José María Alesia entre los años 1973 y 1978. Analiza los lazos políticos, sindicales, barriales y familiares de los trabajadores navales, protagonistas de esta historia. A lo largo del libro, estas particularidades se encuentran articuladas con el contexto político general, lo cual permite al lector vislumbrar el proceso de forma cabal. La obra es una profundización de un trabajo anterior del autor, Los zapatos de Carlito (2007), cuestión que le resta originalidad a algunos de sus planteos. No obstante la minuciosidad esgrimida demuestra los avances de la investigación de Lorenz, superando en calidad a su anterior ensayo.

Algo parecido a la felicidad se divide en tres partes. En la primera de ellas, narra los orígenes de la agrupación teniendo en cuenta las características de las condiciones laborales en Astarsa, la composición de la futura agrupación -que tuvo un origen ideológico heterogéneo aunado por la identificación de los activistas con el clasismo y que finalmente se referenció en la Juventud Trabajadora Peronista (JTP), brazo sindical de Montoneros-, las particularidades del barrio ubicado en el Canal de San Fernando, y el conflicto que derivó en la toma del astillero a fines de mayo de 1973 a raíz de la muerte del trabajador Alesia en circunstancias poco claras y que implican una serie de interrogantes y reflexiones a la luz del presente a los que Lorenz dedica el capitulo final del libro.

El segundo y tercer apartado resultan centrales tanto porque observamos el devenir del conflicto como porque allí encontramos los alcances y los ejes problemáticos de la obra. En la segunda parte el autor analiza la dinámica del proceso de lucha desde la consolidación 
de la agrupación Alesia hasta la antesala del Rodrigazo en el cual tuvo una participación destacada en la zona norte del Gran Buenos Aires. Comenzando con la ocupación de Astarsa, la primera toma exitosa durante el gobierno de Cámpora, Lorenz describe la importante incidencia de la agrupación en el astillero (conformando íntegramente la comisión interna) para hacer efectivas las conquistas logradas tras el conflicto de mayo de 1973. Una de las principales reivindicaciones fue la creación de la Comisión de Higiene y Salud que "marcó un modo de incidencia directa de los obreros en la planificación y control de la producción" (p. 145). De esta forma, le disputaban efectivamente el control de la producción a la patronal y a la dirección del Sindicato Obrero de la Industria Naval (SOIN) -controlada por la burocracia enfrentada con la JTP- como nunca antes había ocurrido.

La cúpula del SOIN formaria una alianza con los directivos de la empresa y las fuerzas represivas estatales y parapoliciales (la Triple A, el Comando de Organización y Concentración Universitaria: la "Santísima Trinidad"), agudizando el conflicto y aumentando los niveles de violencia a finales de 1973. En el capítulo que refiere a los conflictos en Mestrina (el otro astillero de la zona en la que la JTP mantuvo un fuerte enfrentamiento con la SOIN y la patronal), Lorenz señala que "tanto los miembros de la JTP como la ortodoxia sindical apelaron a la fuerza para sostener ese enfrentamiento, que en definitiva relegó el conflicto gremial: patotas armadas dentro y fuera del astillero, intimidaciones, golpizas y secuestros" (p. 178). Esta afirmación resulta problemática porque corre el riesgo de escindir la violencia política de la lucha gremial y, así, caer en el discurso que contextualiza esta etapa como un conflicto entre dos "demonios" con escaso o nulo arraigo en la sociedad. En este pasaje de su trabajo, el autor no parece tener en cuenta que los objetivos de la clase dominante y el origen histórico de la represión estatal y paraestatal en colaboración con la burocracia sindical contra las organizaciones de base no pueden entenderse sólo como una respuesta al militarismo propuesto por agrupaciones como Montoneros. Para llegar a esta conclusión resultaría necesario profundizar el análisis acerca de la represión estatal, los ataques de la burocracia sindical contra las organizaciones de base y la legitimación de la violencia política por estas últimas como respuesta legítima a esas agresiones.

Este presupuesto también se encuentra presente en la tercera parte cuando Lorenz describe el derrumbe de la agrupación Alesia a partir de 1975. Si bien, por un lado, en esta sección contribuye a desmantelar la noción que postula el inicio del plan sistemático de terrorismo el 24 de marzo de 1976, demostrando en el espacio de investigación que la violencia estatal con estas características y dirigidas contra delegados y comisiones internas se inició en los últimos meses del gobierno pe- 
ronista; por otro, parece ubicar en un mismo plano la represión con la estrategia militarista de Montoneros. Señala que desde los meses previos al golpe de Estado los activistas navales "debían dejar hogar, esposas e hijos, proyectos familiares que iniciaron en paralelo a su militancia en la Agrupación. [...] Marca [...] los límites del acompañamiento al proyecto político revolucionario: no se trataba solamente de que la represión y los asesinatos de los escuadrones de la muerte los habían alejado de sus bases y ahuyentaba a los simpatizantes, sino que la propio práctica política se alejaba, por la dinámica de los acontecimientos, del interés, la comprensión y las posibilidades de los trabajadores" (pp. 236, 237). Resulta necesario para llegar a esta conclusión comparar este caso con otros conflictos donde intervinieron organizaciones politicas que no reivindicaban la lucha armada. Si en otras experiencias también los militantes y activistas quedaron aislados del resto de sus compañeros ante la violencia estatal, debería revisarse si es posible igualar los efectos de la represión y las tácticas de las organizaciones armadas.

La mirada del autor en este sentido también parece estar fuertemente influida por el gran peso que tienen las fuentes orales en el libro. Los entrevistados dan su perspectiva en la cual, entre el presente y los acontecimientos relatados, media -entre otros acontecimientos de índole local e internacional- una masacre estatal que no sólo implicó la aniquilación física, sino también el disciplinamiento de los sobrevivientes. Los trabajadores que prestan su versión de los hechos están marcados por esa experiencia. Si bien Lorenz tiene en cuenta esta concepción con respecto a la hija de uno de los activistas desaparecido, por momentos parece basar sus afirmaciones sólo en las subjetividades de los navales, las cuales están atravesadas tanto por la represión de los años 70, como por representaciones dominantes sobre los conflictos de ese periodo reproducidas tanto durante la última dictadura como en estos treinta años de democracia. Estas representaciones negaron o fueron criticas de las luchas sindicales y políticas, muchas de ellas dirigidas por organizaciones armadas. Esta afirmación no implica negar la importancia de la construcción de fuentes orales para profundizar el análisis histórico, sino considerar esta problemática para que el historiador no reproduzca el sentido común que los entrevistados tienen en el presente sobre las luchas obreras del pasado reciente.

Como balance general, Algo parecido a la felicidad resulta un aporte importante acerca de las experiencias y luchas de las organizaciones de base en este periodo y su relación con los partidos políticos, el Estado y la burguesía. También contribuye al debate acerca de la conflictiva relación entre lucha armada y lucha gremial. El trabajo de Lorenz se aleja de miradas simplistas -tanto aquellas que en la actualidad idealizan o demonizan las luchas y experiencias del movimiento obrero en 
los años 70- y arroja luz sobre un período histórico que todavía no ha sido del todo problematizado.

Leandro Molinaro (UBA)

$* * *$

\section{Javier Salcedo, Los Montoneros del barrio, Buenos Aires, Eduntref, 2011, 336 pp.}

En la historiografia argentina existen algunos trabajos que por renovar los puntos de vista en torno a un antiguo objeto, o bien por descubrir uno nuevo, dejan una profunda huella y se convierten en libros canónicos. A su amparo protector florecen líneas de investigación, se validan proyectos de tesis y se desbrozan terrenos incultos del pasado, para convertirlos en fértiles campos de estudio. Revolución y guerra, de Tulio Halperín Donghi, La vieja guardia sindical, de Juan Carlos Torre, y Soldados de Perón, de Richard Gillespie, son algunos ejemplos de estas obras seminales que se convirtieron en algo similar a la noción de paradigma diseñada por Thomas Kuhn. Particularmente, el trabajo de Gillespie ofreció durante varios años un modelo ejemplar para determinar problemas y soluciones provisorias en torno a la historia de la organización político-militar Montoneros. A partir de la llegada a las librerias argentinas de Soldados de Perón, poco a poco se cristalizaron un conjunto de supuestos derivados de la investigación de campo, que se desarrolló prácticamente al filo de los acontecimientos. Aún así, en el prólogo a la segunda edición en español de 1998, el historiador británico afirmaba que no había modificado su tesis fundamental, y que la seguía considerando válida para explicar el surgimiento y la derrota de Montoneros. ¿Cuál es la tesis que menciona el prólogo? Para Gillespie, los Montoneros echaron raíces en las capas medias de la sociedad argentina, pero por su origen pequeño burgués no pudieron o no quisieron insertarse en la clase obrera, decisión que finalmente resultaría fatal para los propósitos de la organización armada. A partir de este supuesto se explicaban distintos aspectos de su organización, como la militarización de sus cuadros y la tardia inserción en la clase obrera a partir de la creación de la Juventud Trabajadora Peronista (JTP) en 1973.

El trabajo de Javier Salcedo tiene el mérito de atreverse a cuestionar algunos de estos planteos iniciales, revisando el caso de los Montoneros de la localidad de Moreno, una experiencia escasamente conocida en el campo de los estudios sobre la izquierda peronista. El libro comparte una filiación común con las investigaciones de Lucas Lanusse sobre los orígenes de Montoneros, de Cristina Viano sobre la formación de Montoneros en Rosario, y de Horacio Robles sobre la Juventud Pero- 